\title{
Robertson, M. y Cavanna, A. (2010). El síndrome de Tourette, segunda edición, Alianza Editorial*
}

\section{Robertson, M. y Cavanna, A. (2010). Tourette Sindrome: FACTS, second edition}

\author{
Inmaculada Escudero Domínguez \\ Universidad Nacional de Educación a Distancia
}

Recientemente ha sido publicada la segunda edición de este libro que, desde nuestra perspectiva, consideramos de gran valor e interés para todos aquellos lectores legos interesados en esta materia, entre los que se encuentran pacientes y familiares, así como psicólogos, profesores, educadores, médicos, asistentes sociales y resto de especialistas que aborden y/o estén interesados en conocer mejor el síndrome de Tourette (ST).

Un aspecto muy notable que destaca en este libro y por lo que lo recomendamos es que su lectura resulta ágil, sencilla y muy comprensible, resumiendo de manera muy acertada lo que se sabe de este síndrome ofreciendo, además, una panorámica muy actualizada y estructurada para el lector no especializado. Las autoras han optado por no incluir referencias bibliográficas y citas científicas a lo largo del texto, lo que facilita aún más su lectura, reduciendo al mínimo el lenguaje científico, pero con muy buen nivel de explicación. No obstante, para aquellas personas interesadas en profundizar en ciertos aspectos relativos al síndrome, las autoras aportan una lista temática y muy completa de referencias bibliográficas al final del libro y asociaciones en España relacionadas con este síndrome.

El libro hace un amplio recorrido sobre las causas de este trastorno, su diagnóstico y manejo terapéutico, ofreciendo información específica sobre los tratamientos y terapias existentes y consejos para el manejo de los síntomas. Aborda también otros desórdenes que pueden confundirse con este síndrome, de cara a Press

* Se publicó originalmente en inglés en 2008 con Oxford University no errar en su diagnóstico. Por último, aporta una valiosa información sobre las asociaciones existentes dirigidas a pacientes y familiares, que podrán acudir a ellas para informarse y recibir apoyo y asesoramiento, con referencia específica a las asociaciones españolas. Se trata, por tanto, de una revisión exhaustiva y rigurosa que ha sido completada con la inclusión de los últimos hallazgos científicos y revisiones teóricas, convirtiéndose así en una guía de gran relevancia para la práctica actual.

La obra se desglosa en 13 capítulos. Los tres primeros se centran en tratar de explicar en qué consiste este síndrome, presentando casos reales de pacientes, sus síntomas, factores influyentes y prevalencia. Así, el capítulo 1, a modo introductorio, trata de mostrar cómo este síndrome se manifiesta de forma muy diferente en cada paciente, abarcando un amplio espectro que va de formas muy leves a formas muy graves. Para ello, presenta tres casos muy distintos, como son los de Johny Thomposon, Tim y Annie, a los que se aludirá de nuevo en capítulos posteriores. Por su parte, el capítulo 2 tiene como objetivo definir este síndrome y describir sus síntomas más comunes, entre los que se encuentran los tics motores y vocales (o fónicos) y la coprolalia. El capítulo 3 aborda la prevalencia del ST y aspectos claves para el diagnóstico como su mayor presencia en personas con problemas de aprendizaje, emocionales y de conducta, personas que requieren educación especial, así como personas con autismo o síndrome de Asperger. Asimismo, las autoras tratan de explicar por qué el ST se diagnostica con más frecuencia en la actualidad, teniendo en cuenta que hasta hace poco este síndrome era extremadamente raro. 
La cuestión relativa al diagnóstico y la evaluación del ST se trata de manera más específica en los capítulos 4, 5 y 6 . Así, el capítulo 4 está especialmente dedicado a mostrar los instrumentos y herramientas que existen en la actualidad para su diagnóstico y evaluación. Este capítulo ofrece una descripción de los síntomas esenciales y característicos del ST, así como de otros rasgos o conductas asociados, y que es necesario conocer para su correcto diagnóstico. Muestra, también, los principios básicos para la evaluación de ST, describiendo las pruebas y escalas estandarizadas disponibles. Al final del capítulo las autoras tratan de explicar por qué este síndrome no se diagnostica en la infancia, siendo un síndrome que se manifiesta de manera más evidente en torno a los 7 años de edad. Por su parte, el capítulo 5 se centra en otros trastornos que pueden confundirse con este síndrome como es el trastorno por tics transitorio, el trastorno por tics múltiples crónico, la distonía, la epilepsia mioclónica u otros trastornos neurológicos en los que el paciente presenta movimientos anómalos. Su conocimiento es esencial de cara a no cometer errores a la hora del diagnóstico. Por último, el capítulo 6 se centra en mostrar otras enfermedades que suelen ir asociadas al ST, como son las conductas obsesivo-compulsivas y el trastorno obsesivo-compulsivo, el trastorno por déficit de atención con hiperactividad, conductas autolesivas, conductas no obscenas pero socialmente inadecuadas, déficits neuropsicológicos leves, depresión, trastorno de oposición desafiante y trastorno de conducta, trastornos de personalidad y trastornos del espectro autista. A lo largo del capítulo se muestra cómo alrededor de un $90 \%$ de los pacientes con ST suelen desarrollar también otras enfermedades, por lo que su conocimiento es también necesario.

Los capítulos 7 y 8 abordan el efecto y las reacciones emocionales que el diagnóstico de ST produce sobre pacientes y familiares y cómo éstos se enfrentan al síndrome. Así, el capítulo 7 aborda una cuestión clave para los pacientes, como es la evolución del síndrome y su pronóstico. Para ello las autoras hacen un recorrido sobre aspectos claves tales como cuándo suele manifestarse la enfermedad, cómo evolucionan los síntomas con la edad, qué factores del entorno pueden influir en la gravedad de los síntomas y el efecto que, en general, tiene el ST sobre el paciente y familiares. El capítulo 8, por su parte, muestra las reacciones emocionales que produce su diagnóstico sobre el paciente y las personas que le rodean, tratando sus efectos sobre las relaciones de pareja, hijos, padres y/o resto de familiares y amigos. Las autoras explican también cómo se ve afectada la calidad de vida de estos pacientes, más allá de sus reacciones emocionales. El capítulo se cierra con una serie de recomendaciones de cara a explicar a los niños con ST su enfermedad y a hablar de los problemas asociados con amigos y familiares.

Los capítulos 9 y 10 se centran en las causas del síndrome, abordando tanto aspectos bioquímicos como genéticos y ambientales. El capítulo 9 está dirigido a reflexionar sobre dos de los principales mitos del ST, a saber: "todas las personas con ST son iguales" y "sólo hay un tipo de ST". A lo largo del capítulo las autoras muestran cómo es posible concluir que existe más de un tipo de ST gracias a las investigaciones recientes realizadas sobre el fenotipo del ST. El capítulo 10, por su parte, muestra cómo su causa es compleja, ya que se compone de influencias genéticas, determinadas infecciones, dificultades durante el embarazo y el nacimiento y posibles influencias hormonales, desarrolladas a lo largo del capítulo. Los capítulos 11 y 12 se centran en el tratamiento y manejo del síndrome, haciendo un amplio recorrido sobre las terapias y medicamentos actuales (capítulo 11) y destacando la importancia que tiene para los pacientes su inclusión en la sociedad (capítulo 12). Para finalizar, las autoras dedican un último capítulo a destacar personas de relevancia social y/o histórica que han sufrido este síndrome, en un esfuerzo por acercar su realidad al lector.

Como ya señalábamos en los primeros párrafos, entre las principales aportaciones de esta obra cabe destacar su carácter divulgador, su facilidad de comprensión, su relevancia y actualidad. Se trata de un libro que trata de recoger las principales aportaciones derivadas de las últimas investigaciones científicas realizadas, en un esfuerzo por hacer asequible su contenido a cualquier lector. 